\title{
KEMAMPUAN MEMECAHKAN MASALAH MATEMATIKA KELAS X IPS SMA WIJAYA PUTRA SURABAYA PADA MATERI SISTEM PERSAMAAN LINEAR TIGA VARIABEL DENGAN TEORI POLYA
}

\author{
Subaidah \\ Program Studi Pendidikan Matematika, STKIP Bina Insan Mandiri \\ subaidah@stkipbim.ac.id
}

\begin{abstract}
Abstrak
Penelitian ini bertujuan untuk mendeskripsikan kemampuan memecahkan masalah matematika kelas X IPS SMA Wijaya Putra Surabaya pada materi sistem persamaan linear tiga variabel dengan teori polya. Penelitian ini merupakan penelitian deskriptif dengan pendekatan kualitatif. Pendekatan kualitatif digunakan dalam mendeskripsikan bagaimana kemampuan memecahkan masalah matematika siswa kelas X IPS SMA Wijaya Putra Surabaya pada materi Sistem Persamaan Linear Tiga Variabel dengan menggunakan teori polya. Kemampuan memecahkan masalah adalah suatu tindakan untuk menyelesaikan masalah atau proses yang menggunakan kekuatan dan manfaat matematika dalam menyelesaikan masalah, yang juga merupakan metode penemuan solusi melalui tahap-tahap pemecahan masalah. Subjek dalam penelitian ini adalah 33 Siswa Kelas X IPS Wijaya Putra Surabaya yang terdiri dari 14 laki-laki dan 19 perempuan. Data diperoleh dari hasil Tes yang sudah dikerjakan oleh siswa. Instrumen yang digunakan adalah Soal Tes Pemecahan Masalah (TPM ) yang memuat masalah sistem persamaan linear tiga variabel yaitu dengan membuat soal tes berbentuk soal cerita yang telah divalidasi oleh validator lalu diberikan kepada siswa untuk dikerjakan sehingga hasil tes tersebut dapat dianalisis oleh peneliti.Analisis seluruh data dilakukan dengan langkah-langkah: reduksi data, paparan data dan menarik kesimpulan. Hasil penelitian menujukan bahwa dari 3 butir soal cerita yang dikerjakan oleh siswa dalam menyelesaikan masalah pada materi Sistem Persamaan Linear Tiga Variabel pada kelas X IPS peneliti memperoleh tiga kategori skor yang dicapai oleh siswa kelas X IPS yaitu kategori mampu, sedang dan kurang. Siswa yang berkategori mampu sebanyak 19, siswa yang berkategori sedang sebanyak 12, dan siswa yang berkategori kurang sebanyak 2. Dengan demikian, dapat disimpulkan bahwa kemampuan siswa kelas X IPS dalam memecahkan masalah matematika yang berbentuk soal cerita tergolong pada kategori mampu.
\end{abstract}

Kata Kunci: Kemampuan, masalah matematika, Sistem persamaan linear tiga variabel, Teori Polya

\begin{abstract}
This study aims to describing the ability to solve mathematical problems in class X IPS students of SMA Wijaya Putra Surabaya in the material system of linear equations of three variables the theory of polya.This Reseach is a qualitative descriptive study. A qualitative approach is used in describing how the ability to solve mathematical problems in class X IPS students of SMA Wijaya Putra Surabaya in the material system of linear equations of three variables using the theory of polya.The ability to solve problems is an action to solve a problem or process that uses the power and benefist of mathematics in solving problems, Which is also a method of finding solutions through the stages of problem solving. The population in this study were 33 students of class X IPS SMA Wijaya Putra Surabaya consisting of 14 men and 19 women. Data was obtained from the results of tests that had been done by students. The instrument used is a Problem Solving Test (TPM) Problem which contains a system of linear equations three variables, namely by making test questions in the from of story questions that have been validated by the validator then given to students to work on so that the test results can be analyzed by the researcher. Analysis of all data is done by steps: data reduction, data exposure, and drawing conclusions. The results of the study showed that of the story done by students in solving problems in the material system of three variable linear equations in the IPS X class the researcher obtained three categories of scores achieved by students of class X IPS, namely the categories of capable, moderate, and less. 19 categorized capable students, 12 moderate categorized students, and 2 less categorized students. Thus, it can be concluded that the ability
\end{abstract}


of IPS X students in solving mathematical problems in the form of story problems belongs to the category of capable.

Key Words: Ability, Problem mathematics, System of Linear Equations Three Variables, Polya Theory. a

\section{PENDAHULUAN}

Matematika merupakan ilmu universal yang memegang peranan penting dalam proses perkembangan teknologi modern, dimana penerapannya mencakup berbagai bidang ilmu pengetahuan dan memajukan daya pikir manusia, BSNP (2006). Oleh karna itu, Pusat Kurikulum,(2002) menyatahkan bahwa tujuan pembelajaran matematika pada jenjang pendidikan dasar dan pendidikan menenga adalah untuk mempersiapkan siswa agar sanggup menghadapi perubahan keadaan didalam kehidupan dan dunia yang selalu berkembang melalui latihan dan tindakan atas dasar pemikiran secara logis, rasional, kritis, cermat,jujur, dan efisien.

Salah satu kompetensi dasar keterampilan dalam kurikulum matematika kelas X edisi revisi 2016 adalah mampu menyelesaikan masalah-masalah berkaitan dengan sistem persamaan linear tiga variabel, Mendikbud (2016). Kompetensi tersebut dapat tercapai melalui pembelajaran yang menekankan pada pengonstruksian konsep secara bermakna,dan penggunaan masalah dalam kelas.

Menurut Florida Deparment of Education, (2010); Ministry of Education (2006) masalah matematika juga membantu siswa mengaitkan pengetahuan yang dipelajari dalam kelas dengan kehidupan sehari-hari, dan dengan pengetahuan lainnya. Hal yang berbeda dengan masalah matematika siswa perlu memikirkan rencana penyelesaian masalah. Menurut Polya (1973) Pembuatan rencana merupakan salah satu tahap pemecahan masalah, secara umum ada empat tahap yaitu memahami masalah, membuat rencana, melaksanakan rencana, dan memeriksa kembali penyelesaian.

Untuk mempermudah melakukan pemecahan masalah pada materi Sistem Persamaan Linear Tiga Variabel (SPLTV) kelas X SMA Wijaya Putra maka dalam teori polya menggunakan empat langgkah/fase penyelesaian masalah. Menurut polya Nur dan Rahman, (2013) memperkenalkan model, prosedur atau langkah-langkah pemecahan masalah matematika yang terdiri atas tahapantahapan pemecahan masalah yaitu : memahami masalah (understanding the problem), membuat rencana (devising a plan), melaksanakan rencana pemecahan (carryng out plan), dan menelaah kembali (looking back). Tahapan pemecahan masalah polya tersebut merupakan aspekaspek yang banyak digunakan untuk mengukur kemampuan pemecahan maasalah.

Hakikat matematika berkenan dengan ide-ide, struktur-struktur dan hubunganhubungannya yang diatur menurut urutan yang logis. Menurut Johnson dan Rising, matematika adalah pola berpikir. Ini merupakan suatu pembuktian yang logis, matematika adalah suatu bahasa dengan menggunakan istilah yang dapat didefinisikan secara akurat, cermat dan jelas.

Menurut Julita (2017) Kemampuan pemecahan masalah merupakan kemampuan memproses informasi dan menyusun berbagai alternatif pemecahan masalah untuk mencapai tujuan yang diinginkan. Menurut Polya dalam Faizah, (2012: 14), kemampuan memecahkan masalah sebagai salah satu usaha untuk mencari jalan keluar dari suatu kesulitan guna mencapai suatu tujuan yang tidak begitu segerah didapat.

Menurut Saad \& Ghani (2008: 119), masalah matematika didefinisikan sebagai situasi yang memiliki tujuan yang jelas tetapi berhadapan dengan halangan akibat kurangnya algoritma yang diketahui untuk menguraikannya agar memperoleh sebuah solusi. Dari penjelasan diatas dapat disimpulkan bahwa kemampuan memecahkan masalah matematika adalah sebagai salah satu usaha untuk mencari 
jalan keluar dari suatu kesulitan guna mencapai suatu tujuan yang tidak begitu segerah didapat sebagai situasi yang memiliki tujuan yang jelas tetapi berhadapan dengan halangan akibat kurangnya algoritma yang diketahui untuk menguraikannya agar memperoleh sebuah solusi.

Dalam memecahkan masalah begitu banyak teori-teori belajar yang dapat digunakan dalam menyelesaikan masalah diantaranya adalah teori belajar skinner, teori belajar vygotsky, teori belajar bruner, dan teori belajar polya. Dalam penelitian ini, saya menggunakan teori belajar polya, karena teori ini mampu mendidik siswa berpikir secara sistematis,dan mampu menganalisis suatu masalah dari berbagai aspek sehingga akan lebih mudah bagi siswa untuk menyelesaikan berbagai soal matematika khususnya soal cerita.

Menurut Polya (1973:5-17), ada empat tahap dalam memecahkan masalah yaitu : (a) Memahami masalah (understand the problem). Pada penyelesaian masalah tahap pertama yang dilakukan siswa adalah memahami soal dan mengidentifikasi apa yang diketahui, apa saja yang ada, jumlah, hubungan, dan nilai-nilai yang terkait serta apa yang dicari; (b) Membuat Rencana (devise a plan). Siswa mampu menyusun rencana atau mengidentifikasi operasi yang terlibat serta strategi yang diperlukan untuk menyelesaikan masalah yang diberikan; (c) Melaksanakan Rencana (carry out the plan). Siswa mampu menyelesaikan masalah dan perlu menerapkan rencana yang sudah dipilih. jika rencana tersebut dianggap kurang tepat maka siswa dapat memilih cara atau rencana lain yang dianggap tepat; (d) Melihat Kembali (looking back). Siswa harus mengecek kembali langkah-langkah yang diterapkan dalam menyelesaikan masalah apakah semua informasi yang penting telah teridentifikasi, mempertimbangkan apakah solusinya tepat, jika dianggap belum tepat dapat melihat alternatif penyelesaian yang lain, dan membaca kembali pertanyaan apakah pertanyaan sudah terjawab.

Dalam kemampuan memecahkan masalah pada matematika sekolah, peneliti mengambil materi Sistem Persamaan Linear
Tiga Variabel (SPLTV) kelas X SMA Wijaya Putra. Siswa diharapkan dapat mengeluarkan kemampuanya untuk menyelesaikan masalah yang diberikan pada materi sistem persamaan linear tiga variabel yang berbentuk soal cerita. Peneliti tertarik mengambil materi tentang sistem persamaan linear tiga variabel karena materi ini selalu berkaitan dengan kehidupan sehari-hari sehingga akan memudahkan siswa dalam berpikir.

Berdasarkan uraian di atas, tujuan penelitian adalah mendeskripsikan kemampuan memecahkan masalah matematika siswa kelas X SMA Wijaya Putra Surabaya Pada materi Sistem Persamaan Linear Tiga Variabel dengan menggunakan teori polya.

\section{METODE}

Penelitian ini menggunakan pendekatan kualitatif. Subjek penelitian adalah siswa kelas X IPS SMA Wijaya Putra Surabaya. Instrumen penelitian terdiri dari dua, yaitu instrumen utama dan instrumen bantu, dimana instrumen utama yaitu peneliti. Instrumen bantunya adalah Soal Tes Pemecahan Masalah (TPM) yang memuat masalah sistem persamaan linear tiga variabel.

Teknik pengumpulan data yang digunakan yaitu dengan memberikan penjelasan kepada siswa tentang Sistem Persamaan Linier Tiga Variabel (SPLTV) menggunakan teori polya dan memastikan siswa memahami penjelasan serta menguji pemahaman siswa dengan memberikan tes matematika dalam bentuk soal cerita. Peneliti memberikan tiga soal untuk menguji kemampuan belajar siswa khususnya pada materi sistem persamaan linear tiga variabel yang berbentuk soal cerita. Siswa mengerjakan soal menggunakan teori polya. peneliti akan melakukan pengumpulan data dari hasil penelitian melalui hasil tes tersebut.

Teknik analisis data yang digunakan dalam penelitian ini sesuai dari kriteria skor kemampuan yang dicapai siswa. Data yang telah didapatkan akan diteliti oleh penulis sesuai kriteria kemampuan yang harus dicapai. Adapun kriteria-kriteria yang harus dicapai seperti pada Tabel 1. 
Tabel 1. Kategori Skor Pencapaian Siswa Tiap Nomor

\begin{tabular}{|c|c|}
\hline Kategori & Keterangan \\
\hline $5-6$ & Mampu \\
\hline $3-4$ & Sedang \\
\hline $0-2$ & Kurang \\
\hline
\end{tabular}

Data dapat dijumlahkan secara keseluruhan setelah memperoleh data dari tiap nomor soal. Peneliti dapat melihat kemampuan siswa dari pencapaian skor yang didapatkan sesuai kriteria kemampuan dalam menyelesaikan beberapa soal cerita.

Kategori pencapaian siswa dapat dilihat pada Tabel 2.

Tabel 2. Kategori Pencapaian Siswa secara Keseluruhan

\begin{tabular}{|c|c|}
\hline Kategori & Keterangan \\
\hline $13 \leq \mathrm{n} \leq 18$ & Mampu \\
\hline $6 \leq \mathrm{n} \leq 12$ & Sedang \\
\hline $0 \leq \mathrm{n} \leq 5$ & Kurang \\
\hline
\end{tabular}

\section{HASIL DAN PEMBAHASAN} berikut:

Hasil tes siswa dipaparkan sebagai

Tabel 3. Skor Pencapaian Secara Keseluruhan Dari Siswa

\begin{tabular}{|c|c|c|c|c|c|c|}
\hline No & Nama Siswa & Soal No. 1 & Soal No. 2 & Soal No. 3 & Total & Keterangan \\
\hline 1 & Achmad. A. Affuddin & 5 & 6 & 4 & 15 & Mampu \\
\hline 2 & Alfina Damayanti & 4 & 4 & 5 & 13 & Mampu \\
\hline 3 & Alivia Rizki & 4 & 3 & 6 & 13 & Mampu \\
\hline 4 & Andini Nadiawati & 6 & 6 & 6 & 18 & Mampu \\
\hline 5 & Angel I.F. Wijaya & 6 & 4 & 6 & 16 & Mampu \\
\hline 6 & Anisa N. Hidayah & 5 & 3 & 5 & 13 & Mampu \\
\hline 7 & Aryan H. P. Utomo & 4 & 4 & 5 & 13 & Mampu \\
\hline 8 & Balqis Zahiyah & 6 & 6 & 2 & 14 & Mampu \\
\hline 9 & Daniel W. Putra & 6 & 6 & 1 & 13 & Mampu \\
\hline 10 & Diffa R. Pratama & 6 & 4 & 3 & 13 & Mampu \\
\hline 11 & Dyah M. K. G. Pratiwi & 6 & 0 & 0 & 6 & Sedang \\
\hline 12 & Ferghie S. Pramudyah & 6 & 3 & 1 & 10 & Sedang \\
\hline 13 & Gusti W. Ananto & 6 & 5 & 2 & 13 & Mampu \\
\hline 14 & Happy N. Virdiana & 6 & 6 & 6 & 18 & Mampu \\
\hline 15 & Harrel Ciddan & 5 & 4 & 5 & 14 & Mampu \\
\hline 16 & Helingga A.P.P. Santo & 6 & 4 & 2 & 12 & Sedang \\
\hline 17 & Ika S. Hidayanti & 5 & 4 & 2 & 11 & Sedang \\
\hline 18 & Isman A. Saputro & 6 & 4 & 2 & 12 & Sedang \\
\hline 19 & Istya N. Kurniawanty & 4 & 4 & 6 & 14 & Mampu \\
\hline 20 & Juliani Wulandari & 6 & 6 & 6 & 18 & Mampu \\
\hline 21 & Kuncoro A. Wibawa & 6 & 0 & 2 & 8 & Sedang \\
\hline 22 & Meidia A. Prima & 6 & 4 & 2 & 12 & Sedang \\
\hline 23 & Mersanty Monteiro & 3 & 4 & 6 & 13 & Mampu \\
\hline 24 & Moch. E.P. Sugiono & 6 & 4 & 2 & 12 & Sedang \\
\hline 25 & Muh. Willian Y. Satrio & 5 & 1 & 2 & 8 & Sedang \\
\hline 26 & Muh. S.A. Danova & 2 & 3 & 0 & 5 & Kurang \\
\hline 27 & Rensa Aprilliyah & 5 & 1 & 6 & 12 & Sedang \\
\hline 28 & Silvi Novitasari & 6 & 6 & 6 & 18 & Mampu \\
\hline 29 & Syahfira E. Supono & 6 & 6 & 6 & 18 & Mampu \\
\hline 30 & Tania M. Imanona & 2 & 2 & 1 & 5 & Kurang \\
\hline 31 & Titan M. Romanisti & 4 & 5 & 6 & 15 & Mampu \\
\hline 32 & Wahyu Kurniawan & 3 & 4 & 2 & 9 & Sedang \\
\hline 33 & Yayu M. S. Karoho & 4 & 4 & 4 & 12 & Sedang \\
\hline
\end{tabular}

Pada soal no. 1, diketahui 22 siswa kategori mampu, 9 siswa kategori sedang, dan 2 siswa kategori kurang. Pada soal no.2 siswa yang dikatakan mampu sebanyak 11 , yang dikatakan sedang sebanyak 17 dan yang dikatakan kurang sebanyak 5. Pada soal no.3, yang dinyatakan mampu 
sebanyak 14 siswa, yang sedang sebanyak 4 siswa dan yang kurang sebanyak 15 siswa.

Sesudah data dari hasil pekerjaan siswa terkumpul, selanjutnya peneliti menganalisis data siswa untuk mengetahui kemampuan siswa dalam menyelesaikan masalah (soal) pada materi SPLTV.

Sesuai dengan hasil pekerjaan siswa dalam menyelesaikan masalah pada materi sistem persamaan linear tiga variabel (SPLTV) dengan soal sebanyak 3 nomor. Siswa yang dikatakan mampu jika mencapai skor $13 \leq \mathrm{n} \leq 18$ sebanyak 19 siswa, yang dikatakan sedang jika mencapai skor $6 \leq \mathrm{n} \leq 12$ sebanyak 12 siswa, dan dikatakan kurang jika mencapai skor $0 \leq \mathrm{n}$ $\leq 5$ sebanyak 2 orang.

Soal Nomor 1, peneliti mendapatkan skor yang dicapai kelas X IPS terdiri dari tiga kategori yaitu : kategori mampu, kategori sedang dan kategori kurang. Dikatakan kategori mampu karena siswa menuliskan jawaban dengan baik, tepat, dan benar sesuai dengan kriteria - kriteria penskoran dalam soal.Siswa menuliskan pemisalan variabel dengan baik, menuliskan apa yang diketahui dan menuliskan apa yang ditanyakan dengan baik. Siswa benar-benar teliti membaca soal sehingga siswa bisa menuliskan model matematika pada jawaban dengan baik,menuliskan hasil akhir dengan baik dan dapat memberikan kesimpulan pada jawaban dengan baik.

Dikatakan kategori sedang karena siswa tidak menuliskan jawaban dengan baik,tepat, lengkap dan benar, tidak sesuai dengan kriteria-kriteria penskoran dalam soal. Siswa menuliskan variabel dengan baik tapi siswa tidak menuliskan apa yang diketahui dan tidak menuliskan apa yang ditanyakan dalam soal, mungkin karena siswa tidak teliti dalam membaca soal dan tidak memahami maksud dari isi soal. Siswa menuliskan jawabannya dengan baik, mampu mengoprasikan cara kerja dalam soal sehingga siswa menuliskan hasil akhir dengan baik dan dapat membuat kesimpulan dari jawaban dengan baik .

Dikatakan kategori kurang karena siswa tidak menuliskan jawaban dengan baik, tepat, lengkap dan benar, tidak sesuai dengan kriteria-kriteria penskoran dalam soal. Siswa tidak menuliskan pemisalan variabel mungkin karena siswa tidak memahami masalah (soal). Siswa tidak menuliskan apa yang diketahui dan tidak menuliskan apa yang ditanyakan mungkin karena siswa tidak memahami masalah (soal),siswa tidak membaca soal dengan teliti, dan siswa hanya terfokus pada jawaban saja. Siswa menuliskan jawaban dengan baik mungkin karena siswa paham cara mengubah soal cerita kedalam bentuk matematika, Siswa juga menuliskan hasil akhir dengan baik, tapi tidak dapat membuat kesimpulan dari jawaban tersebut.

Soal Nomor 2, peneliti mendapatkan skor yang dicapai oleh kelas X IPS yang terdiri dari tiga kategori yaitu kategori mampu,kategori sedang dan kategori kurang. Dikatakan kategori mampu karena siswa menuliskan jawaban dengan baik, tepat, dan benar sesuai dengan kriteria kriteria penskoran dalam soal.Siswa menuliskan pemisalan variabel dengan baik, menuliskan apa yang diketahui dan menuliskan apa yang ditanyakan dengan baik. Siswa benar-benar teliti memabaca soal sehingga siswa bisa menuliskan model matematika pada jawaban dengan baik,menuliskan hasil akhir dengan baik dan dapat memberikan kesimpulan pada jawaban dengan baik.

Dikatakan kategori sedang karena siswa tidak menuliskan jawaban dengan baik, tepat, lengkap dan benar, tidak sesuai dengan kriteria-kriteria penskoran dalam soal. Siswa tidak menuliskan variabel dengan baik, siswa tidak menuliskan apa yang diketahui dan tidak menuliskan apa yang ditanyakan dalam soal, mungkin karena siswa tidak teliti dalam membaca soal, tidak memahami maksud dari isi soal dan siswa hanya terfokus untuk langsung menuliskan jawabanya saja. Siswa menuliskan jawabannya dengan baik, mampu mengoprasikan cara kerja dalam soal sehingga siswa menuliskan hasil akhir dengan baik dan dapat membuat kesimpulan dari jawaban dengan baik.

Dikatakan kategori kurang karena siswa tidak menuliskan jawaban dengan baik, tepat, lengkap dan benar, tidak sesuai dengan kriteria-kriteria penskoran dalam soal. Siswa tidak menuliskan pemisalan 
variabel mungkin karena siswa tidak memahami masalah (soal).

Siswa tidak menuliskan apa yang diketahui dan tidak menuliskan apa yang ditanyakan mungkin karena siswa tidak memahami masalah (soal), siswa tidak membaca soal dengan teliti, dan siswa hanya terfokus pada jawaban saja. Siswa menuliskan jawaban dengan baik mungkin karena siswa paham cara mengubah soal cerita kedalam bentuk matematika, Siswa tidak menuliskan hasil akhir dengan benar, dan tidak dapat membuat kesimpulan dari jawaban tersebut.

Soal Nomor 3, peneliti mendapatkan skor yang dicapai oleh kelas X IPS yang terdiri dari tiga kategori yaitu kategori mampu, kategori sedang dan kategori kurang. Dikatakan kategori mampu karena siswa menuliskan jawaban dengan baik, tepat, dan benar sesuai dengan kriteriakriteria penskoran dalam soal.Siswa menuliskan pemisalan variabel dengan baik, menuliskan apa yang diketahui dan menuliskan apa yang ditanyakan dengan baik. Siswa benar-benar teliti memabaca soal sehingga siswa bisa menuliskan model matematika pada jawaban dengan baik, menuliskan hasil akhir dengan baik dan dapat memberikan kesimpulan pada jawaban dengan baik.

Dikatakan kategori sedang karena siswa tidak menuliskan jawaban dengan baik, tepat, lengkap dan benar, tidak sesuai dengan kriteria-kriteria penskoran dalam soal. Siswa menuliskan pemisalan variabel dengan baik. Siswa tidak menuliskan apa yang diketahui dan tidak menuliskan apa yang ditanyakan dalam soal, mungkin karena siswa tidak teliti dalam membaca soal, tidak memahami maksud dari isi soal dan siswa hanya terfokus untuk langsung menuliskan jawabanya saja. Siswa menuliskan jawabannya dengan baik, mampu mengoprasikan cara kerja dalam soal sehingga siswa menuliskan hasil akhir dengan baik dan dapat membuat kesimpulan dari jawaban dengan baik .

Dikatakan kategori kurang karena siswa tidak menuliskan jawaban dengan baik, tepat, lengkap dan benar, tidak sesuai dengan kriteria-kriteria penskoran dalam soal. Siswa menuliskan pemisalan variabel dengan baik. Siswa tidak menuliskan apa yang diketahui dan tidak menuliskan apa yang ditanyakan mungkin karena siswa tidak memahami masalah (soal), siswa tidak membaca soal dengan teliti, dan siswa hanya terfokus pada jawaban saja. Siswa menuliskan jawaban dengan baik mungkin karena siswa paham cara mengubah soal cerita kedalam bentuk matematika. Siswa tidak menuliskan hasil akhir dengan benar, dan tidak dapat membuat kesimpulan dari jawaban dengan baik.

Dari paparan hasil kerja siswa dalam menyelesaikan masalah pada materi sistem persamaan linear tiga variable (SPLTV) pada kelas X IPS dengan jumlah soal cerita sebanyak 3 butir, peneliti mendapatkan tiga kategori skor yang dicapai oleh siswa kelas $\mathrm{X}$ IPS, yaitu kategori mampu, kategori sedang, dan kategori kurang.

Kategori mampu sebanyak 19 siswa, kategori sedang sebanyak 12 siswa, dan kategori kurang sebanyak 2 siswa. Dengan demikian, kemampuan dalam memecahkan masalah matematika yang berupa soal cerita pada kelas X IPS berada pada kategori mampu. Siswa perlu belajar lagi mengenai kriteria-kriteria atau langkah-langkah dalam menyelesaikan soal cerita, karena masih ada siswa yang tidak menuliskan pemisalan, tidak menuliskan apa yang diketahui, tidak menuliskan apa yang ditanyakan dan tidak menuliskan kesimpulan.

\section{SIMPULAN}

Berdasarkan hasil analisis Kemampuan Memecahkan Masalah Matematika pada Kelas X IPS SMA Wijaya Putra Surabaya Pada Materi Sistem Persamaan Linear Tiga Variabel (SPLTV) dengan menggunakan Teori Polya dapat dikategorikan mampu dengan skor $13 \leq n \leq 18$ sebanyak 19 siswa, kategori sedang dengan skor $6 \leq n \leq$ 12 sebanyak 12 siswa, dan kategori kurang dengan skor $0 \leq n \leq 5$ sebanyak 2 siswa. Berdasarkan hasil tersebut dapat disimpulkan bahwa kemampuan siswa kelas X IPS SMA Wijaya Putra dalam memecahkan masalah pada materi SPLTV khususnya pada soal cerita tergolong mampu. 
DAFTAR PUSTAKA

BNSP. (2006). Panduan Penyusunan Kurikulum Tingkat Satuan Pendidikan Jenjang Pendidikan Dasar dan Menengah. Jakarta: Badan Standar Nasional Pendidikan.

Florida Departement of Education. (2010). Clasroom Cognitive and Meetacognitive Strategies for Teachers. Tallahassee, Florida: Bureau of Exceptional Education and Student Services.

Mendikbud. (2016). Peraturan Mentri Pendidikan dan Kebudayaan. Nomor 24 tahun 2016. Jakarta, Indonesia: Author.

Nur, A. S. Rahman, A. (2013). Pemecahan Masalah Matematika Sebagai Sarana
Mengembangkan Penalaran Formal Siswa Sekolah Menengah Pertama. Jurnal sainsmat, 1(2),84-92.

Polya, G. 1973. How To Solve It. New Jersey; Princeton University Press.

Saad, N.S. \& Ghani, A. S. 2008. Teaching Mathematics in Secondary School: Theories and Practices. Perak: University Pendidikan Sultan Idris.

Suherman, dkk. 1999. Strategi Pembelajaran Matematika Kontemporer. Bandung: Universitas Pendidikan Indonesia.

Sumarmo. 2002. Pembelajaran Matematika Untuk Mendukung Pelaksanaan Kurikulum Berbasis Kompetensi. Makalah Disajikan Pada Pelatihan Guru MTS. Bandung. 